\title{
Is tissue the issue?
}

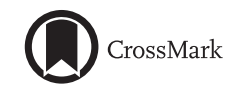

\author{
Brian E. Louie, MD, MHA, MPH, FRCSC, FACS
}

\author{
From the Division of Thoracic Surgery, Swedish Cancer Institute, Seattle, Wash. \\ Disclosures: Author has nothing to disclose with regard to commercial support. \\ Received for publication March 18, 2017; accepted for publication March 21, 2017. \\ Address for reprints: Brian E. Louie, MD, MHA, MPH, FRCSC, FACS, Division of Thoracic Surgery, Swedish \\ Cancer Institute and Medical Center, Suite 900, 1101 Madison St, Seattle, WA 98105 (E-mail: brian.louie@ \\ swedish.org). \\ J Thorac Cardiovasc Surg 2017;153:1598-9 \\ 0022-5223/\$36.00 \\ Copyright $\subset 2017$ by The American Association for Thoracic Surgery \\ http://dx.doi.org/10.1016/j.jtcvs.2017.03.099
}

Clinical acumen is a concept describing a surgeon's ability to make a diagnosis and subsequent treatment decisions based on the available clinical data surmised from a patient's history and the supporting diagnostic investigations. Traditionally, thoracic surgeons needed an accurate history, an appropriate physical examination, and a chest radiograph identifying a spiculated lesion to make a diagnosis of lung cancer. It was expected that a negative result would occur in a small percentage of patients who did not have a lung cancer to not miss curing an early cancer.

In the article "Biopsy First: Lessons Learned From Cancer and Leukemia Group B (CALGB) 140503," Kohman and colleagues ${ }^{1}$ challenge our clinical acumen. They analyzed patients with presumed non-small cell lung cancer preregistered for enrollment into Cancer and Leukemia Group B 140503, a multicenter randomized trial that just closed enrollment. They reviewed the reasons patients failed to undergo randomization within the study. As a result, they provide a glimpse into how patients with a solitary lung nodule less than $2 \mathrm{~cm}$ are managed in major centers across North America.

At the heart of this discussion is the probability that a pulmonary nodule less than $2 \mathrm{~cm}$ is, in fact, a primary lung cancer. Approximately 1 in 5 preregistered patients with presumed lung cancer in this trial were found to have benign disease at surgery, before randomization, suggesting that our assessment of pulmonary nodules is inaccurate. Kohman and colleagues $^{1}$ suggest that a pretreatment biopsy could have avoided "unnecessary surgery" in these patients. Similar rates of resection of benign disease have been reported in prior trials. ${ }^{2,3}$ One also has to consider that there remains a "not so insignificant" risk of mortality, potential morbidity, and cost after any lung surgery, especially in patients with compromised lung function.

In an era when many small nodules are detected incidentally or in lung cancer screening programs, the clinical acumen of thoracic surgeons is being challenged. The patients are no longer older men who smoke and have spiculated lesions. We are now frequently seeing younger, female patients with subcentimeter and semisolid nodules. There is a need for thoracic surgeons to enhance

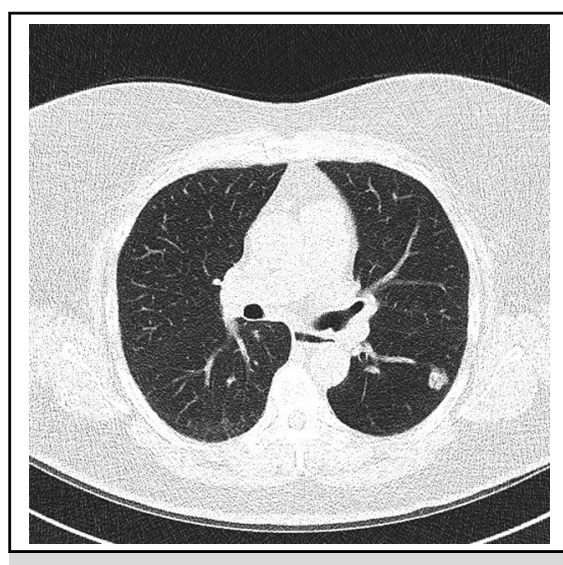

Small peripheral lung nodules: Are they always lung cancer?

\section{Central Message}

Thoracic surgeons are challenged to adjunct their clinical experience with a mathematical prediction model and judicious use of preoperative biopsy when assessing cancer risk in a pulmonary nodule.

See Article page 1592 .

their clinical acumen when confronted by such patients. It is likely that a preoperative biopsy in this trial would have clarified the diagnosis, and futile surgery could have been avoided, but a biopsy also can be nondiagnostic and complicated. Additional tools are being developed to help us enhance our clinical acumen. Examples are mathematical predication models to estimate the cancerous risk of nodules, such as the Mayo Model, ${ }^{4}$ PanCan, ${ }^{5}$ or Thoracic Research Evaluation and Treatment (TREAT), ${ }^{6}$ and the analysis of brush cytology of the main bronchus collected during bronchoscopy by bronchial genomic gene-expression classifier.

Similar to general surgeons who are using modern tools to reduce the rate of negative appendectomy, thoracic surgeons are challenged to adjunct their clinical experience with modern-day tools that may help us reduce unnecessary surgery for nonmalignant nodules, whether by using mathematical prediction models, the judicious use of preoperative biopsy, or even possibly genomic gene analysis of bronchial cytology.

\section{References}

1. Kohman LJ, Gu L, Altorki N, Scalzetti E, Veit LJ, Wallen JM, et al. Biopsy first: lessons learned from Cancer and Leukemia Group B (CALGB) 140503. J Thorac Cardiovasc Surg. 2017;153:1592-7. 
2. Veronesi G, Bellomi M, Scanagatta P, Preda L, Rampinelli C, Guarize J, et al. Difficulties encountered managing nodules detected during a computed tomography lung cancer screening program. J Thorac Cardiovasc Surg. 2008;136:611-7.

3. Kuo E, Bharat A, Bontumasi N, Sanchez C, Zoole JB, Patterson GA, et al. Impact of video-assisted thoracoscopic surgery on benign resections for solitary pulmonary nodules. Ann Thorac Surg. 2012;93:266-73.

4. Swensen SJ, Silverstein MD, Ilstrup DM, Schleck CD, Edell ES. The probability of malignancy in solitary pulmonary nodules. Application to small radiologically indeterminate nodules. Arch Intern Med. 1997;157:849-55.
5. McWilliams A, Tammemagi MC, Mayo JR, Roberts H, Liu G, Soghrati K, et al Probability of cancer in pulmonary nodules detected on first screening CT. N Engl J Med. 2013;369:910-9.

6. Deppen SA, Blume JD, Aldrich MC, Fletcher SA, Massion PP, Walker RC, et al Predicting lung cancer prior to surgical resection in patients with lung nodules. J Thorac Oncol. 2014;9:1477-84.

7. Silvestri GA, Vachani A, Whitney D, Elashoff M, Porta Smith K, Ferguson JS et al. A bronchial genomic classifier for the diagnostic evaluation of lung cancer. N Engl J Med. 2015;373:243-51. 